\title{
Quantification of active materials and antioxidants in some medicinal plants and their antibacterial effects
}

\author{
Inas M. Khamis ${ }^{1,2}$ and Ahmed A. Aly ${ }^{1}$
}

\author{
${ }^{1}$ Medicinal and Aromatic Plant Department, Desert Research Center, Ministry of Agriculture and \\ Land Reclamation, Egypt. \\ ${ }^{2}$ Biology Department, the University College - Alkhafji, Hafr Al-Batin University, Kigdom of Saudi \\ Arabia (KSA).
}

Received: 15 Oct. 2019 / Accepted 10 Nov. / Publication date: 30 Dec. 2019

\begin{abstract}
Commonly used plants, especially in Arab societies, are Punica granatum, Laurus Nobilis and Aloe vera, which have the largest share to be considered for this study and to determine whether they can be used as antioxidants and as antibacterial to many pathogenic bacterial strains. The study was carried out on five samples; peel pomegranate fruit, laurel leaves, Whole cactus leaf, cactus leaf after the removal of the gel and the cactus gel only. The five studied extracts were found to be free of anthocyanins and cardiac glycosides. The highest percentage of total phenols and flavonoids were found in Punica granatum; and the lowest percentage were found in the Aloe vera gel extract. On contrast, the highest percentage of tannins was in Laurus Nobilis leaves and the lowest percentage was extracted from the leaves of Aloe vera without gel. When determining the values of $\mathrm{IC}_{50}$, Punica granatum peel, Laurus Nobilis leaves and total Aloe vera leaves were found to have antioxidant activity due to their ability to capture free radicals. The antimicrobial study revealed that, the ten strains of pathogenic bacteria with effect on six strains from them. The highest effect was found for Punica granatum peel extract on staphylococcus aureus, Staphylococcus epidermidis, while the lowest effect was for Punica granatum peel extract with $6 \mathrm{~mm}$ inhibition zone and extract of total Aloe vera leaves on Klebsiella pneumoniae and gel extract on Staphylococcus aureus with $8 \mathrm{~mm}$ inhibition zone. Therefore, it is recommended to use Punica granatum peel, Laurus Nobilis leaves and Aloe vera leaves as antioxidant and antibacterial against many pathogenic bacterial strains. It should also consider the use of whole Aloe vera leaves, not gel only because they contain high concentration of active materials higher than those found in gels.
\end{abstract}

Keywords: Pomegranate, Laurel, Cactus, Phenols, Flavonoids, Tannins, Antioxidant, Antibacterial.

\section{Introduction}

Medicinal plants have been used from ancient time for their medicinal values. Nowadays, the crude extracts samples from medicinal plants have been shown interest for the development and preparation of alternative traditional medicine (Chatoui et al., 2008). Plants are the best sources for chemical ingredients or phytochemical agents for cure of different diseases. Medicinal plants are an inexhaustible source of molecules with very different biological and pharmacological activities.

The use of plants and its derivative products for medical purposes represents a practice in increasing expansion at the present time. This practice is based primarily on the popular knowledge, passed from generation to generation, but has been incorporating scientific advances in the search to guarantee security using plant species with proven therapeutic efficacy (Barroso et al., 2018). condiments are used worldwide to increase and/or add flavor to food and, secondarily, for conservation purposes, due to its antimicrobial and antioxidant properties. The condiments of the Lamiaceae family, for example, have been widely used in food products such as Laurus nobilis L. (Barroso et al., 2018). In popular medicine is used against digestive disorders and flatulence, ulcer treatment, menstrual cramps and oligomenorrhea (Speroni et al., 2011).

The pomegranate, Punica granatum L., is one of the oldest known edible fruits. Punica granatum L. has been widely used by traditional medicine in America, Asia, Africa and Europe for the treatment of different types of diseases. In the ancient Egyptian culture, the pomegranate fruit was

Corresponding Author: Inas M. Khamis, Medicinal and Aromatic Plant Department, Desert Research Center, Ministry of Agriculture and Land Reclamation, Egypt and Biology Department, the University College, Alkhafji, Hafr Al-Batin University, Kingdom of Saudi Arabia. 
regarded as a symbol of prosperity and ambition, making it common practice to decorate sarcophagi with depictions of the plant. According to Eber's Paprus (one of the oldest medical writings, dated circa 1,500 BC), the plant was used by the Egyptians as a treatment for tapeworm and other parasitic infestations. The fruits of Punica granatum (pomegranate) have been used to treat acidosis, dysentery, microbial infections, diarrhea, helminthiasis, and respiratory pathologies (Duman et al., 2009). Furthermore, this plant appears to have interesting antiviral activity. Pomegranate extracts have been shown to be effective against the herpes virus (Zhang, et al., 1995) and hydroalcoholic extracts of whole fruits have exhibited high activity against the influenza virus. In recent years, there has been an increasing interest in determining antioxidant properties of red fruits, due to their rich dietary sources of antioxidant phenolics and anthocyanins (Duman et al., 2009).

Laurus Nobilis plant, belonging to Lauracea family grown in Europe and USA as an ornamental plant. It is cultivated for aromatic oil, found in its leaves, in Turkey, Algeria, Morocco, Portugal, Spain, Italy, France and Mexico (Kivrak et al., 2017). The volatile oils obtained from the leaves of L. nobilis still maintains the importance in both traditional and modern medicine with its pharmacological activities. Studies have shown that $L$. nobilis volatile oil has antioxidant (Basak and Candan, 2013), anticonvulsant, analgesic, anti-inflammatory, antiviral, anticholinergic, antibacterial and antifungal activities (Kivrak et al., 2017). L. nobilis, which is a powerful medicinal and aromatic plant with these pharmacological properties, has been reported in cosmetic uses. $L$. nobilis leaf volatile oil is used for the preparation of hair lotion due to its antidandruff activity and for the treatment of psoriasis (Kivrak et al., 2017).

Aloe vera, a succulent perennial and drought resisting plant, is well known for its therapeutic potential. Their leaves contains contain $99 \%$ water and many secondary metabolites such as complex polyphenols (e.g., tannins and flavonoids), lignins, saponins, anthraquinones, glycoproteins, polysaccharides, enzymes and also smaller metabolites, like sterols, fatty acids, alcohols, vitamins, amino acids, and saccharides (Saad and Abdul kareem, 2017; Lopez, et al., 2017; Lucini et al., 2014). Aloe vera showed a $10 \mathrm{~mm}$ inhibition activity on Klebsiella bacteria. The Aloe vera leaf extract showed a $20 \%$ inhibition against many isolates of Gram-positive bacteria, and the gel also showed significant activity against Gram-negative and negative germs (Orooba, 2012). Aloe vera extract works as antimicrobial and antibacterial, antiviral and various fungi along with its potency as an antioxidant (Vidic et al., 2014). A number of beneficial effects of Aloe vera have been reported, including immunomodulatory, wound and burn healing, hypoglycemic, anticancer, gastro-protective, antifungal, and anti-inflammatory properties. These beneficial therapeutic properties of Aloe vera have been employed for several commercial applications.

The present review provides a survey of literature on its composition, rheology, processing and pharmaceutical uses as well as an outline of its application in foods and cosmetics. In addition, complications associated with the use of Aloe vera and relevant precautions are summarized. Chemical characterization of Aloe vera is in progress through scientific developments in the area of analytical chemistry. It is expected that further information will be available at a faster rate soon, resulting in enhanced applications (Maan, et al., 2018).

\section{Material and Methods}

\section{Extracts:}

Whole plant Samples from each treatment were soaked separately with ethyl alcohol $70 \%$ in conical flasks for $24 \mathrm{~h}$ at $40^{\circ} \mathrm{C}$ on water bath. After 24 hours it was filtered with Whatman No.1 filter paper. The filtrates were evaporated with rotary evaporator apparatus to obtained extraction for each sample. The extracts were stored in sample bottles at $4^{\circ} \mathrm{C}$ prior to use for further analyses.

\section{Determination of Total Phenolic Content (TPC):}

The total phenolic content for all plant samples was determined by using Folin- Ciocalteu method (Odabasoglu, et al., 2004).

\section{Determination of Total Flavonoids (TFC):}

The total flavonoids content for all plant samples was determined was estimated according to Odabasoglu, et al., (2004). 


\section{Determination of Total Tannins (TTC):}

The total tannins content for all plant samples was determined was estimated according to Ali, et al., (1991).

\section{Antioxidant Scavenging Activity (DPPH) Assay:}

The effect of methanolic extracts on DPPH (2,2- diphenyl-1-picrylhydrazyl) radicals was estimated according to Gardeli, et al., (2008).

\section{Antimicrobial activities:}

The tested microorganisms included the following bacteria: Staphylococcus aureus, Escherichia coli, Klebsiella pneumoniae, Streptococcus pyogenes, Streptococcus agalactiae and Staphylococcus epidermidis, were used in Disk-diffusion assay according to the protocol described by Hajlaoui et al. (2009).

\section{Results and Discussions}

\section{Determination of Total Phenolic Content (TPC):}

From the quantitative estimation of the total phenolic content of the plant samples being studied as shown in table (1), the highest percentage of total phenols in pomegranate peels extract and followed by Laurus leaves extract ( $8.822 \& 8.721 \%$, respectively).

On contrast, the total phenolic content reached the lowest percentage in Aloe vera gel extract and then gradually increased in the leaves without gel and finally in the total leaf $(3.220 ; 3.541 \&$ $3.621 \%$, respectively).

\section{Determination of Total Flavonoid (TFC):}

Total flavonoids present in different studied plant extracts were determined spectrophotometrically and calculated as question. From table (1), the percentages of total flavonoids reached their maximum values in pomegranate peels extract (13.412 \%), followed by Laurus Nobilis leaves $(8.383 \%)$, and decreased to the lowest concentration in Aloe vera gel (3.811\%). Flavonoids are important dietary compounds, having a capacity to inhibit DNA damage and lipid peroxidation, and to quench free radicals; they also have anti-carcinogenic and anti-proliferative effects (Romanova and Vachalkova, 1999).

Table 1: Determination of total active materials for the plant extracts

\begin{tabular}{lccccc}
\hline & $\begin{array}{c}\text { Punica granatum } \\
\text { L. }\end{array}$ & $\begin{array}{c}\text { Laurus Nobilis } \\
\text { L. }\end{array}$ & Total leaf & $\begin{array}{c}\text { Aloe vera } \text { L. } \\
\text { Leaf without gel }\end{array}$ & gel \\
\hline Total Phenolics \% & 8.822 & 8.721 & 3.621 & 3.541 & 3.220 \\
Total Flavonoids \% & 13.412 & 8.383 & 6.321 & 5.211 & 3.811 \\
Total Tannins \% & 17.231 & 19.452 & 11.259 & 10.213 & 12.561 \\
IC $_{\mathbf{5 0} \text { antioxidant } \boldsymbol{\mu g} / \mathbf{m l}}$ & 0.761 & 0.650 & 0.630 & 0.261 & 0.381 \\
\hline
\end{tabular}

\section{Determination of Total Tannins (TTC):}

We determined the content of tannins in studied plants to evaluate the economical values of the plant. The percentages of total tannins (Table 1) showed that the total tannins reached their maximum values in Laurus Nobilis leaf extract (19.452 \%), followed by pomegranate peels (17.231\%), while the lowest percentage was in extracts of Aloe vera leaves without gel $(10.213 \%)$ and this results was agreement with Kivrak et al., (2017) and Kaurinovic et al., (2010). In the total tannins content in the various extracts of the Aloe vera leaf, we find the lowest percentage of leaves without gel and the highest percentage was in gel, as it was $10.213 \& 12.561 \%$, respectively.

\section{Antioxidant Scavenging Activity (DPPH) Assay:}

The $\mathrm{IC}_{50}$ values as shown in table 2, where it was found that pomegranate peels, Laurus Nobilis leaves and total Aloe vera leaves possess high antioxidant effectiveness due to its ability to capture the free radicals as $0.761 ; 0.650 \& 0.630 \mu \mathrm{g} / \mathrm{ml}$, respectively. Thus, the pomegranate peels are the highest antioxidant extracts, followed by the Laurus Nobilis leaf extract, and the total Aloe vera 
leaves. The $\mathrm{IC}_{50}$ values in three different extracts of Aloe vera plants, showed that, the leaf extract without gel, was given the lowest values as an antioxidant activity of $0.261 \mu \mathrm{g} / \mathrm{ml}$ and this agrees with a previous report (Vidic et al., 2014).

\section{Antimicrobial activities:}

The initial detection of the extracts of the studied plants was done as antimicrobials on ten types of pathogenic bacteria as shown in table (2). Effectiveness was given and the inhibition diameter was measured for six types, Staphylococcus aureus, Staphylococcus epidermidis, Streptococcus agalactiae, Klebsiella pneumoniae, E. coli \& Streptococcus pyogenes while four other types of bacteria strains (Pseudomonas aeruginosa, Salmonella typhi, Enterococcusi spp. and Neisseria gonorrhea) are resisted to the extracts under study. It was observed from the obtained results Looking at the initial survey of the pomegranate extract as antimicrobials, we find the effectiveness of this extract on many pathogenic bacteria, including Staphylococcus aureus, Staphylococcus epidermidis, Streptococcus agalactiae \& Klebsiella pneumoniae with an inhibition zone 12, 16, 28 \& $16 \mathrm{~mm}$, Respectively and this agrees with a previous report (Kulkarni and Aradhya, 2005). Laurel leaf extract also have inhibition effects against Streptococcus pyogenes, Staphylococcus aureus and Streptococcus agalactiae by an inhibition zone diameter of about 18,15 and $13 \mathrm{~mm}$, respectively (Table 2).

On cactus extracts and their effect on bacterial strains, all three extracts of cactus were affected on Staphylococcus aureus \& Staphylococcus epidermidis, and the highest effect was for Staphylococcus aureus. The total leaves extract $(23 \mathrm{~mm})$ was the highest effect for bacteria. For the gel extract only $18 \mathrm{~mm}$ and this result was agreement with Orooba and Ibrahim (2012) \& Benzidia et al., (2018). In general, we find that the highest effect was for pomegranate extracts on Staphylococcus aureus and Staphylococcus epidermidis with a inhibition zone $28 \mathrm{~mm}$ in diameter, while the lowest effect was for pomegranate peel extract with a diameter of $6 \mathrm{~mm}$ following the total cactus leaf extract on Klebsiella pneumoniae and gel extract on bacteria Staphylococcus aureus with $8 \mathrm{~mm}$ inhibition diameter.

Table 2: Antimicrobial activities for the plant extracts

\begin{tabular}{lccccc}
\hline \multicolumn{1}{c}{ Plant extract } & \multicolumn{5}{c}{ inhibition zone (mm) } \\
\cline { 2 - 6 } Bacteria straines & $\begin{array}{c}\text { Punica granatum } \\
\text { L. }\end{array}$ & $\begin{array}{c}\text { Laurus } \\
\text { Nobilis L. }\end{array}$ & Total leaf & $\begin{array}{c}\text { Aloe vera L. } \\
\text { Leaf without gel }\end{array}$ & gel \\
\hline Staphylococcus aureus & 28 & 15 & 23 & 9 & 8 \\
Escherichia coli & $-\mathrm{ve}$ & $-\mathrm{ve}$ & 19 & $-\mathrm{ve}$ & $-\mathrm{ve}$ \\
Klebsiella pneumoniae & 6 & $-\mathrm{ve}$ & 8 & $-\mathrm{ve}$ & $-\mathrm{ve}$ \\
Streptococcus pyogenes & $-\mathrm{ve}$ & 18 & $-\mathrm{ve}$ & $-\mathrm{ve}$ & 9 \\
Streptococcus agalactiae & 12 & 13 & $-\mathrm{ve}$ & $-\mathrm{ve}$ & $-\mathrm{ve}$ \\
Staphylococcus epidermidis & 28 & $-\mathrm{ve}$ & 16 & 11 & 18 \\
Pseudomonas aeruginosa & $-\mathrm{ve}$ & $-\mathrm{ve}$ & $-\mathrm{ve}$ & $-\mathrm{ve}$ & $-\mathrm{ve}$ \\
Salmonella typhi & $-\mathrm{ve}$ & $-\mathrm{ve}$ & $-\mathrm{ve}$ & $-\mathrm{ve}$ & $-\mathrm{ve}$ \\
Enterococcus spp. & $-\mathrm{ve}$ & $-\mathrm{ve}$ & $-\mathrm{ve}$ & $-\mathrm{ve}$ & $-\mathrm{ve}$ \\
Neisseria gonorrhae & $-\mathrm{ve}$ & $-\mathrm{ve}$ & $-\mathrm{ve}$ & $-\mathrm{ve}$ & $-\mathrm{ve}$ \\
\hline
\end{tabular}

The percentage of phenolic, flavonoids and tannins with pomegranate peels about 8.822 ; $13.412 \& 17.231 \%$, respectively. Upon returning to the results of the detection of the effectiveness of this plant as an antioxidant, we find that the $\mathrm{IC}_{50}$ of this plant was estimated at about $0.761 \mu \mathrm{g} / \mathrm{ml}$. This indicates that these compounds has the ability to prevent oxidation and resist free radicals, which play the most important role in the development of many serious diseases such as cancer and blockage of the arteries, as well as anti-inflammatory and diabetes, and this was confirmed by many scientists (Wu and Tian, 2017). The importance of the laurel plant as antioxidant, antibacterial, antifungal and antiviral in addition to its use as anti-inflammatory and that plant extracts are used on a wide field in alternative medicine to the effective contents of volatile oils, tannins, flavonoids and other secondary compounds (Barroso et al., 2018; Kivrak et al., 2017; Basak and Candan, 2013; \& Ozacan et al., 2010.

Many scientists recemented using the Aloe vera plant leaves and not the gel only in many therapeutic and pharmacological activities, that have been proved by research, the Aloe vera leaf plant or removed gel contains the highest concentration of phenols and flavonoids compared with the gel 
only. These active substances are characterized by their donor ability of hydrogen, which makes the plant as antioxidant (Lucini et al., 2014).

\section{Conclusion}

The results of the research showed that the content of the active substances in the three plants under study is very high, even though the top of the pomegranate peels and the Laurel leaves, and the least Aloe vera leaves, have proven their ability as antioxidants where these compounds are able to slow or prevent oxidation of molecules by removing free radicals known as electrolytes free and thus protect the cells of the human body from its many dangers, so that it is the best protection for the human body from many diseases such as infection and various cancerous tumors. Therefore, it is recommended to use these plants as antioxidants and antibacterial. It was also recommended that when using Aloe vera plants for different uses, including the manufacture of cosmetics and creams for skin rejuvenation, and that our use is not limited to gel only because it was actually proven that the paper parts without gel contain a higher percentage of some of the active substances available with the gel only.

\section{References}

Ali, A.A., S.A. Ross, M.K. Mesbah, and S.A. El-Moghazy, 1991. Phytochemical Study of Lemonium axillare Forssk. Pull. Fac. Pharm. Cairo Univ., 29(3): 59-62.

Barroso, W.A., R.S.D.Gondim, V.B. Marques, M.M. Lael, P.F. Santos, T.O. Castro, F.F.S. Filho, D.N. Sousa, A. Melo, and C.M. Vilanova, 2018. Pharmacognostic Characterization of Laurus nobilis L. Leaves. Journal of Chemical and Pharmaceutical Research, 10(1): 30-37.

Basak, S.S., and F. Candan, 2013. Effect of Laurus nobilis L. essential oil and its main components on $\alpha$-glucosidase and reactive oxygen species scavenging activity, Iranian Journal of Pharmaceutical Research, 12(2): 367-379.

Benzidia, B., M. Barbouchi, H. Hammouch, N. Belahbib, M. Zouorhi, H. Erramli, N.A. Daoud, N. Badrane, and N. Hajjaji, 2018. Chemical compositiom and antioxidant activity of tannins extract jram green rind of Aloe vera L. burm. F. journal of king saud university. journal home page: $1-7$.

Chatoui, K., A. Talbaoui, A., Aneb, M., Bakri, Y., Harhar, H. and M. Tabyaoui, 2008. Phytochemical Screening, Antioxidant and Antibacterial activity of Lepidium sativum seeds from Morocco. J. Mater. Environ. Sci. 7(8): 2938-2946.

Duman, A.D., M. Ozgen, K.S. Dayisoylu, N. Erbil, and C. Durgae, 2009. Antimicrobial activity of six Pomegranata (Punica granatum L.) Varieties and their relation to some of their Pomological and Phytonutrient cheracteristics. Jourrnal molecules, 14: 1808-1817.

Gardeli, C., V. Papageorgiou, A. Mallouchos, T.Kibouris,and M. Komaitis, 2008. Essential oil composition of Pistacia lentiscus L. and Myrtus communis L. Evaluation of antioxidant capacity of methanolic extracts. Food Chem. 107: 1120-1130.

Hajlaoui, H., N. Trabelsi, E. Noumi, M. Snoussi, H. Fallah, R. Ksouri, and A. Bakhrouf, 2009. Biological activities of the essential oils and methanol extract of tow cultivated mint species (Mentha longifolia and Mentha pulegium) used in the Tunisian folkloric medicine. World. J. Microbiol. Biotechnol., 25: 2227-2238.

Kaurinovic, B., M. Popovic, and S. Vlaisavljevic, 2010. In vitro and in vivo effects of Laurus nobilis L. leaf extracts. Molecules, 15(2): 3378-3390.

Kivrak, I., M.E. Duru, M. Öztürk, N. Mercan, M. Harmandar and G. Topçu, 2017. Antioxidant, Anticholinesterase and antimicrobial constituents from the essential oil and ethanol extract of Salvia potentillifolia, Food Chemistry, 116: 470-479.

Kulkarni, A.P., and S.M. Aradhya, 2005. Chemical changes and antioxidant activity in pomegranate arils during fruit development Food Chem. 93:319-324.

Lopez, Z., G. Nunez-Jinez, G. Avalos-Novarro, G. Rivera, J. Salazar-Flores, J.A. Raminez, B.A. AyilGutierreze, and P. Knauth, 2017. Antioxidant and cytotoxicological effects of Aloe vera food supplements. Journal of food Quality., 1-10. 
Lucini, L., M. Pellizzoni, R. Pellegrino, G.P. Molinari, and G. Colla, 2014. Phytochemical constituents and in vitro radical scavenging activity of different Aloe sp. Food chemistry, 170:501-507.

Maan, A.A., A. Nazir, M.I. Khan, T. Ahmad, R. Zia, M. Murid, and M. Abrar, 2018. The therapeutic properties and applications of Aloe vera. Journal of Herbal Medicine. 12(1): 1-10.

Odabasoglu, F., A. Aslan, A. Cakir, H. Suleyman, Y. Karago, and M. Halici, 2004. Comparison of antioxidant activity and phenolic content of three lichen species. Phytotherapy Research, 18 (11): 938-941.

Orooba, M. and S. Ibrahim, 2012. Evaluation of anti-bacterial activity of Capparis spinose (ALkabara) and Aloe vera extracts against Isolates Bacterial Skin Wound Infection in-vitro and in-vivo. Kufa Journal for Veterinary Medical Sciences, 3 (2): 23-35

Ozacan, B., M. Esen, M. Sangun, A. Coleri, and M. Caliskan, 2010. Effective antibacterial and antioxidant properties of methanolic extract of Laurus nobilis seed oil, Journal of Environmental Biology, 31(5): 637-641.

Romanova, D., and A. Vachalkova, 1999. UV spectrometric and DC Polarographic studies on apigenin and luteolin. Archives of Pharmacal Research; 22 (2): 173-178.

Saad, A.J.A., and N.F. Abdulkareem, 2017. Antioxidont and Antimicrobial Activity of Cactus (Aloe vera) Leaves Extract Against Pathogenic Bacteria. Journal of Agricultural Research. 4(4):3948.

Speroni, E., R. Cervellati, S. Dall'acqua, M.C. Guerra, E. Greco, P. Govoni, and G. Innocenti, 2011. Gastroprotective effect and antioxidant properties of different Laurus nobilis L. leaf extracts J Med Food. 14(5):499-504

Vidic, D., E. Taric, J. Alagic, and M. Maksimovic, 2014. Determination of total phenolic content and antioxidant activity of ethanol extracts from Aloe spp. Bulletin of the Chemists and Technologists of Bosnia and Herzegovina. 42: 5-10.

$\mathrm{Wu}, \mathrm{S}$. and L. Tian, 2017. Diverse phytochemicals and Bioactivities in the ancient fruit and modern functional food pomegranate. Journal molecules. 22 (1606): 1-17.

Zhang J., B. Zhan, X. Yao, Y. Gao, and J. Shong 2015. Antiviral activity of tannin from the pericarp of Punica granatum L. against genital Herpes virus in vitro. Zhongguo Zhong Yao Za Zhi., 20:556-558. 